\title{
Somatic Embryogenesis and Plant Regeneration from Zygotic Embryo in Carica papaya L., cv. Red-Lady
}

\author{
Md. Humayun Kabir ${ }^{1, ~ *, ~ M d . ~ Z i a u r ~ R a h m a n ~}{ }^{2}$, Ahmad Nazri Karim Mamun ${ }^{1}$ \\ ${ }^{1}$ Plant Biotechnology and Genetic Engineering Division, Institute of Food and Radiation Biology, Atomic Energy Research Establishment, \\ Bangladesh Atomic Energy Commission, Savar, Dhaka, Bangladesh \\ ${ }^{2}$ Department of Biofunctional Chemistry, Graduate School of Environmental and Life Science, Okayama University, Okayama, Japan
}

\section{Email address:}

mithu_my@yahoo.com (M. H. Kabir),zrahman_rubd@yahoo.com (M. Z. Rahman), ankmamun@yahoo.com (A. N. K. Mamun)

${ }^{*}$ Corresponding author

\section{To cite this article:}

Md. Humayun Kabir, Md. Ziaur Rahman, Ahmad Nazri Karim Mamun. Somatic Embryogenesis and Plant Regeneration from Zygotic Embryo in Carica papaya L., cv. Red-Lady. Plant. Vol. 4, No. 6, 2016, pp. 45-50. doi: 10.11648/j.plant.20160406.11

Received: August 23, 2016; Accepted: September 8, 2016; Published: October 18, 2016

\begin{abstract}
Somatic embryogenesis creates a number of opportunities to facilitate large-scale propagation, synthetic seed production, genetic improvement through somaclonal variation, in vitro mutagenesis, protoplast fusion and genetic transformation. Induction of somatic embryogenesis from the vegetative parts of papaya plant was met with low success rates and a slow process of regeneration. Success depends on the choice of explants, the species being used and on various methods of embryogenesis will study. The most suitable explant for somatic embryogenesis is a large portion of either meristematic tissue or cell that retain an ability to express totipotency. Various investigations were made on somatic embryo induction of Carica spp. such as ovules of immature fruits, zygotic embryos from immature fruits, axillary buds, peduncles of immature fruits etc. In this study, somatic embryo induction from zygotic embryo of an immature fruit was examined. Various concentrations of 2,4-D and two levels of sucrose concentrations with or without addition of glutamine were assessed to determine the best response for induction of somatic embryogenesis from immature zygotic embryo of immature fruits in papaya cv. Red-lady (Carica papaya L.). The results showed that MS medium supplemented with $5.0 \mathrm{mg} / 1$ 2,4-D + $400 \mathrm{mg} / 1$ glutamine $+60 \mathrm{~g} / \mathrm{l}$ sucrose promoted the formation of highest $(70 \%)$ percentage of somatic embryo and also the average maximum number $(35.80 \pm 4.40)$ of somatic embryo per explant. The highest $(44 \%)$ percentage of somatic embryo germination into complete plantlets were obtained on MS medium devoid of plant growth regulators. The embryo developed only shoots of $22 \%$ and only roots of $10 \%$ instead of complete plantlet formation in this medium of MS0. The average highest $(4.25 \pm 0.32$ $\mathrm{cm}$ ) shoot length per germinated somatic embryo derived complete plantlets were also achieved on MS0 medium. The maximum $(90 \%)$ percentage of root induction and average highest $(7.50 \pm 0.75)$ number of root per somatic embryo derived shoot and also the average maximum $(5.20 \pm 0.40 \mathrm{~cm})$ root length were obtained on MS medium without plant growth regulators. The survival rate of somatic embryo derived plantlets in the field was about $10 \%$ to $50 \%$ depending on management practices.
\end{abstract}

Keywords: Somatic Embryogenesis, Regeneration, Papaya

\section{Introduction}

The quality of human life has been maintained and enhanced for generations by the use of plant and their product. Human have enjoyed eating fresh fruits as recorded history. To-date rising of human population has put a tremendous pressure on plants and their products. Environmental pollution have also accelerated the development of new technologies for plant propagation, breeding and improvement. The combination of biotechnology and conventional methods such as plant propagation and breeding may be novel approach for improving and multiplying a large number of plant varieties. Vegetative propagation by culturing apical and axillary meristems has been explored quite effectively and proved to be a reliable as well as a commercial method for many plant species. To my knowledge, in view of this, papaya not explored yet. In addition, when the number of available 
meristem is not sufficient to support a large-scale vegetative propagation, then use of somatic embryos would be the next best choice. Papaya is an important versatile fruit of the tropics and available year round in the local markets of Bangladesh. It is a wholesome fruit and provides good source of vitamins and minerals in the daily diet of the people [1]. It is also a popular fruit and contains secondary metabolites [2]. The ripened fruit is usually eaten as dessert, processed into jams, juice and soft drink. Besides being nutritious table fruit, an important product of papaya is papain, which is in great demand in the international market. Papain is used in meat tenderizing, manufacture of chewing gum, cosmetics, tannin hides, degumming of natural silk and to give shrink resistance to wool. There are a good number of land races of papaya grown in different parts of the world including Bangladesh. The plant is mainly propagated by seed [ 3 and 4]. In Bangladesh, farmers also usually grown papaya from seeds and sometimes without selection of seedlings. Therefore, the production is varied in quantity and quality. However, India and Brazil is the second largest producer of this fruit in the globe [5]. Naturally, papaya has three sex types of staminate (male), pistillate (female) and hermaphrodite (bisexual), but female and bisexual types are productive. Modern breeding using biotechnological techniques include protoplast fusion [6] and gene transfer via Agrobacterium-mediated method [7] and particle bombardment [8] for tolerant to insect-pest-diseases, prolonged shelf life of fruits or improved other agronomic traits. These techniques require the establishment of in vitro culture system such as induction of somatic embryogenesis and recovery of plantlets from the somatic embryo as plant obtained from single cells are non chimeric. Therefore, the present investigation was undertaken to induce somatic embryogenesis using immature zygotic embryo as explants of locally cultivated papaya cv Red-lady to overcome those variabilities. Although Fitch and Manshardt (1990) established papaya embryogenic culture from immature zygotic embryos, but our study was attempted for understanding usefulness of the seedlings for papaya production and possibility of biotechnological tool being applied in this crop for further improvement.

\section{Materials and Methods}

Red-lady papaya variety is usually hermaphrodite, orange flesh with oblong shape and originated from Mexico. Seedlings were collected from the local market and planted at the field of Atomic Energy Research Establishment. Two to three months old at the weight of 250 to $350 \mathrm{~g}$ immature fruits of papaya cv. Red-lady were harvested from field grown trees in Atomic Energy Research Establishment Campus, Savar, Dhaka. Fruits were surface sterilized in $70 \%$ alcohol for 10 minutes and $40 \%$ clorox for 10 minutes. Thereafter it was rinsed 3 times with sterile distilled water under laminar airflow cabinet. Fruits were bisected under aseptic conditions and seeds were removed and placed on petridishes for embryo excision. Immature seeds were obtained and embryos were isolated to be used as explants. Excised 5 immature whitish zygotic embryos per jar were placed on 0.6 (w/v) agar solidified Murashige and skoog (MS) (1962) [9] media containing 1.0, 2.5 and $5.0 \mathrm{mg} / 1$ 2,4-D alone and also 2,4-D in addition with $400 \mathrm{mg} / \mathrm{l}$ glutamine. The sucrose concentrations were used at $30 \mathrm{~g} / \mathrm{l}$ for each concentrations of 2,4-D and $60 \mathrm{~g} / \mathrm{l}$ for each concentrations of $2,4-\mathrm{D}+400 \mathrm{mg} / \mathrm{l}$ glutamine for the induction of somatic embryogenesis. Subcultures were done 30 days interval on the same inoculation medium for maximum embryo proliferation. The $\mathrm{pH}$ was adjusted to 5.8 prior to autoclaving. Culture media were sterilized by autoclaving at $121^{\circ} \mathrm{C}$ for 15 minutes under $1.1 \mathrm{~kg} / \mathrm{cm}^{2}$ pressure. Five somatic embryos with callus of 90 days old culture were transferred to five germination media of MS0, MS + $0.1 \mathrm{mg} / \mathrm{l} \mathrm{BA}, \mathrm{MS}+0.5$ $\mathrm{mg} / \mathrm{l} \mathrm{BA}, \mathrm{MS}+1.0 \mathrm{mg} / \mathrm{l} \mathrm{BA}$ andMS $+1 \mathrm{mg} / \mathrm{l} \mathrm{BA}+0.1 \mathrm{mg} / \mathrm{l}$ NAA for shoot induction. Morphologically healthy shoots were transferred to half strength MS, MS0 and MS with different concentrations of IBA, IAA and NAA for root induction. One healthy shoot was transferred into jar for root induction. Each treatment contained 10 replicate cultures. All treatments were repeated three times. All the cultures were kept at $25 \pm 2{ }^{\circ} \mathrm{C}$ in growth room with a 16 hour illumination (12.7 $\mu \mathrm{mol} \mathrm{m} \mathrm{m}^{-2} \mathrm{sec}^{-1}$ of light intensity) maintained by cool white fluorescent light. Data were collected on different characters at day 90 for embryo induction and embryo proliferation and at day 30 for embryo germination and also at day 30 for rooting of shoots. Observations on cultures were carried out daily. The experiments were arranged in a completely randomized design (CRD). A descriptive analysis was carried out using the recorded data. Each value represents the Mean \pm standard errors. Somatic embryo raised plantlets were removed carefully from the culture vessels, washed thoroughly to remove traces of nutrient medium, transferred to earthen pots and finally placed outdoor condition for acclimatization. Plantlets in the earthen pots were contained a mixture of sandy-loam soil and compost (2:1) and covered with transparent polyethylene bag for 10 days to ensure high humidity while misted regularly. After two months of acclimation period, 10 plantlets were planted at the experimental field to observe the yield performance over parents. Yield performance was observed 10 to 11 months after transferring plantlets in the field.

\section{Results and Discussion}

A wide range of plant growth regulators on the organogenesis and somatic embryogenesis of papaya in in vitro was tested. The most popular plant growth regulators used in papaya somatic embryogenesis is 2,4-D and given its success across a wide range of cultivars. Phytohormones may determine cellular response of papaya as reported [10]. Use of PEG, activated charcoal and ABA improved quality of somatic embryos in papaya as mentioned [11]. Successful induction of somatic embryogenesis in papaya and successive regeneration into plantlets depends on type of explants and also age of explants used [12]. In the present investigation, after a week of culture period on induction 
medium, cotyledons of zygotic embryos opened up and the apical domes were enlarged. Different shaped with light yellow colour somatic embryos were observed to induced directly from the enlarged apical domes of the zygotic embryo (Figure 1.a). Somatic embryos and callus induction were observed initiation after one month of culture period. Early response of explants to induction of somatic embryogenesis might be due to the effect of competent media composition and best timing of explants used. At higher concentration of 2,4-D with the addition of glutamine as well as higher concentration of sucrose in the media, increased in percentage of somatic embryo formation and number of somatic embryo formed per explant (Table 1). It is an evidence of this study and this might be due to the effect of media composition or genotype or both. The highest percentage $(70 \%)$ of somatic embryo formation and

Table 1. Effect of 2,4-D, glutamine and sucrose concentrations in the background of MS medium on induction of somatic embryo from immature zygotic embryo of Carica papaya L. cv. Red-Lady at 90 days of inoculation period.

\begin{tabular}{|c|c|c|c|c|}
\hline \multicolumn{3}{|c|}{ Concentration of } & \multirow{2}{*}{$\%$ of somatic embryo induction } & \multirow{2}{*}{$\begin{array}{l}\text { No. of somatic embryo/explant } \\
\text { Mean } \pm \text { S.E. }\end{array}$} \\
\hline 2,4-D (mg/l) & Glutamine (mg/l) & $\operatorname{Sucrose}(g / \mathbf{l})$ & & \\
\hline 1.0 & - & 30 & - & - \\
\hline 2.5 & - & 30 & 10 & $3.0 \pm 0.0$ \\
\hline 5.0 & - & 30 & 30 & $4.30 \pm 1.10$ \\
\hline 1.0 & 400 & 60 & 30 & $4.30 \pm 1.50$ \\
\hline 2.5 & 400 & 60 & 50 & $11.40 \pm 2.0$ \\
\hline 5.0 & 400 & 60 & 70 & $35.80 \pm 4.40$ \\
\hline
\end{tabular}

the highest number of somatic embryo per explants $(35.80 \pm$ 4.40) were obtained in medium containing $5.0 \mathrm{mg} / 1$ 2,4-D + $400 \mathrm{mg} / \mathrm{l}$ glutamine $+60 \mathrm{~g} / \mathrm{l}$ sucrose after 90 days of culture period (Table 1), which is more similar to this study reported [13] in papaya var. exotica. Somatic embryogenesis in papaya using 30g/l sucrose concentrations also reported [14]. This is partially supported in our study. Most of the somatic embryos induced directly without any callus induction. Some somatic embryos, however, developed indirectly from the embryogenic callus (Figure 1.b) and some also emerged from the surface of primary globular somatic embryos termed secondary somatic embryos or recurrent embryogenesis. Somatic embryo germination (Figure 1.c) and regenerated into complete plantlets were also observed on MS medium without any hormonal concentrations and combinations. Meanwhile, the highest (44\%) percentage of germination of somatic embryo into complete plantlets was found on MS medium devoid of plant growth regulators (Table 2). Besides, $27 \%$ somatic embryo germinated into complete plantlets on $\mathrm{MS}+0.1 \mathrm{mg} / \mathrm{l} \mathrm{BA}$. On the other hand, only $22 \%$ embryo germinated into shoots and only $10 \%$ germinated into roots on MS medium devoid of plant growth regulators. Similar observation was made by Agus, 2001 in papaya variety exotica. The highest $(4.25 \pm 0.32 \mathrm{~cm})$ average shoot length of an embryo also observed in this medium. The strength of embryo cloning technology and their exploitation for mass propagation was based on recurrent embryogenesis and this recurrent embryogenesis occurs when primary somatic embryos fail to mature normally into plantlets. This is also in agreement with the present study [8] and [15]. The result showed that 2,4-D alone at low concentrations $(1.0 \mathrm{mg} / \mathrm{l}) \mathrm{did}$ not produce somatic embryo at all whilst $30 \%$ with $4.30 \pm$ 1.50 somatic embryo per explants were obtained on medium containing $1 \mathrm{mg} / \mathrm{l}$ 2,4-D + $400 \mathrm{mg} / \mathrm{l}$ glutamine $+60 \mathrm{~g} / \mathrm{l}$ sucrose. This indicated that glutamine with higher concentrations of sucrose had potential effect on somatic embryo proliferation of papaya variety Red-lady. The study showed that somatic embryo formation inhibited due to the absent of glutamine and comparatively low concentrations of sucrose along with low 2,4-D concentrations. This might be due to the poor media composition for explants tissue to stimulate embryogenic cell proliferation. Somatic embryogenesis obtained in papaya using only higher concentrations of 2,4-D with leaf tissue explants was reported [16]. Somatic embryo induction from zygotic embryo in papaya cv. Co.-7 using lower concentrations of 2,4-D also reported [17]. Somatic embryo induction from zygotic embryo was found using 2,4-D alone with $30 \mathrm{~g} / \mathrm{l}$ and also $60 \mathrm{~g} / 1$ sucrose concentrations [12]. All these studies are supported to our present investigation. Mature somatic embryos on transferred to germination media responded differently to different media composition after 30 days of culture period (Table 2). MS medium without growth regulators showed the

Table 2. Regeneration of somatic embryo on MS media with different concentrations and combinations of plant growth regulators at 30 days of inoculation period.

\begin{tabular}{llllll}
\hline \multicolumn{2}{l}{ Growth regulators $(\mathbf{m g} / \mathbf{l})$} & \multicolumn{2}{l}{ \% of somatic embryo germinated into } & \multicolumn{2}{c}{ Shoot length of somatic embryo } \\
\hline BA & NAA & Plantlet & Shoot & Root & (Mean \pm SE)cm. \\
\hline 0 & 0 & 44 & 22 & 10 & $4.25 \pm 0.32$ \\
0.1 & 0 & 27 & 36 & - & $3.10 \pm 0.20$ \\
0.5 & 0 & 10 & 18 & - & $2.50 \pm 0.36$ \\
1.0 & 0 & 0 & 12 & - & $2.25 \pm 0.12$ \\
1.0 & 0.1 & 0 & 26 & - & $3.15 \pm 0.62$ \\
\hline
\end{tabular}

best response (44\%) for germination of somatic embryo into complete plantlets (Figure 1.d). MS medium containing 0.1 $\mathrm{mg} / \mathrm{l} \mathrm{BA}$ and $0.5 \mathrm{mg} / \mathrm{l} \mathrm{BA}$ were showed poor response of $27 \%$ and $10 \%$ respectively for the regeneration of complete 
plantlets. It was observed that germinated somatic embryo produced only shoots accompanied by callus on media containing MS $+1.0 \mathrm{mg} / \mathrm{l} \mathrm{BA}$ that were not converted into complete plants. This might be due to the imbalanced media composition for somatic embryo germinations. In addition, highest somatic embryo germination from zygotic embryo was recorded using the combinations of BA + NAA in MS supplemented media was reported [10]. The rooting responses differed among the auxins used (Table 3). Although IBA was found responsive for root induction but better response was observed on MS medium devoid of plant growth regulators, in which $90 \%$ shoot rooted within 10 to 15 days of culture period. The average number of root per shoot was $7.50 \pm 0.75$ and the average root length of $5.20 \pm 0.40$ $\mathrm{cm}$ were observed in this medium of MS0.Highest rooting efficiency using IBA in papaya somatic embryo derived shoot was mentioned [10]. This study showed highest rooting efficiency using only MS0, which might be due to the effect of genotype or timing of culture initiation or both. Morphologically strong and healthy rooted plantlets were taken out carefully from the culture vessels and washed gently under running tap water to get rid of agar. The in vitro raised somatic embryo derived plantlets were then transferred to earthen pot (Figure 1.e) containing a mixture of soil and compost (2:1) and gradually acclimated and eventually transferred to the natural environment. About $10 \%$ to $50 \%$ of the somatic embryo derived plantlets were survived in natural environment. Embryo derived plantlets were very sensitive to adapt in the outdoor conditions. Misted irrigation with appropriate shading and better management practice can improve survival rate of somatic embryo derived plantlets in the field. Acclimation problem of in vitro embryo derived plantlets of Carica papaya L. was discussed [18]. It was found that out of 10 somatic embryo derived plants grown in the field, all were observed hermaphrodite in morphological appearance. But only seven plants were produced marketable fruits with an average number of 14 to 32 fruits per tree and an average weight of 650 to $750 \mathrm{~g}$ per fruit whilst parents produced 27 to 38 fruits per tree and average fruit weight was 850 to $1075 \mathrm{~g}$ (Data not shown). Data were collected at the maturation stage of 9 to 11 months. No pathogen attack was observed during the growing period of 10 to 12 months in the field. The technique of in vitro culture has reached a level of sophistication where plant tissue and organs can be broken down to fully viable single cells and whole plant reconstituted from the individual cells via shoot-bud

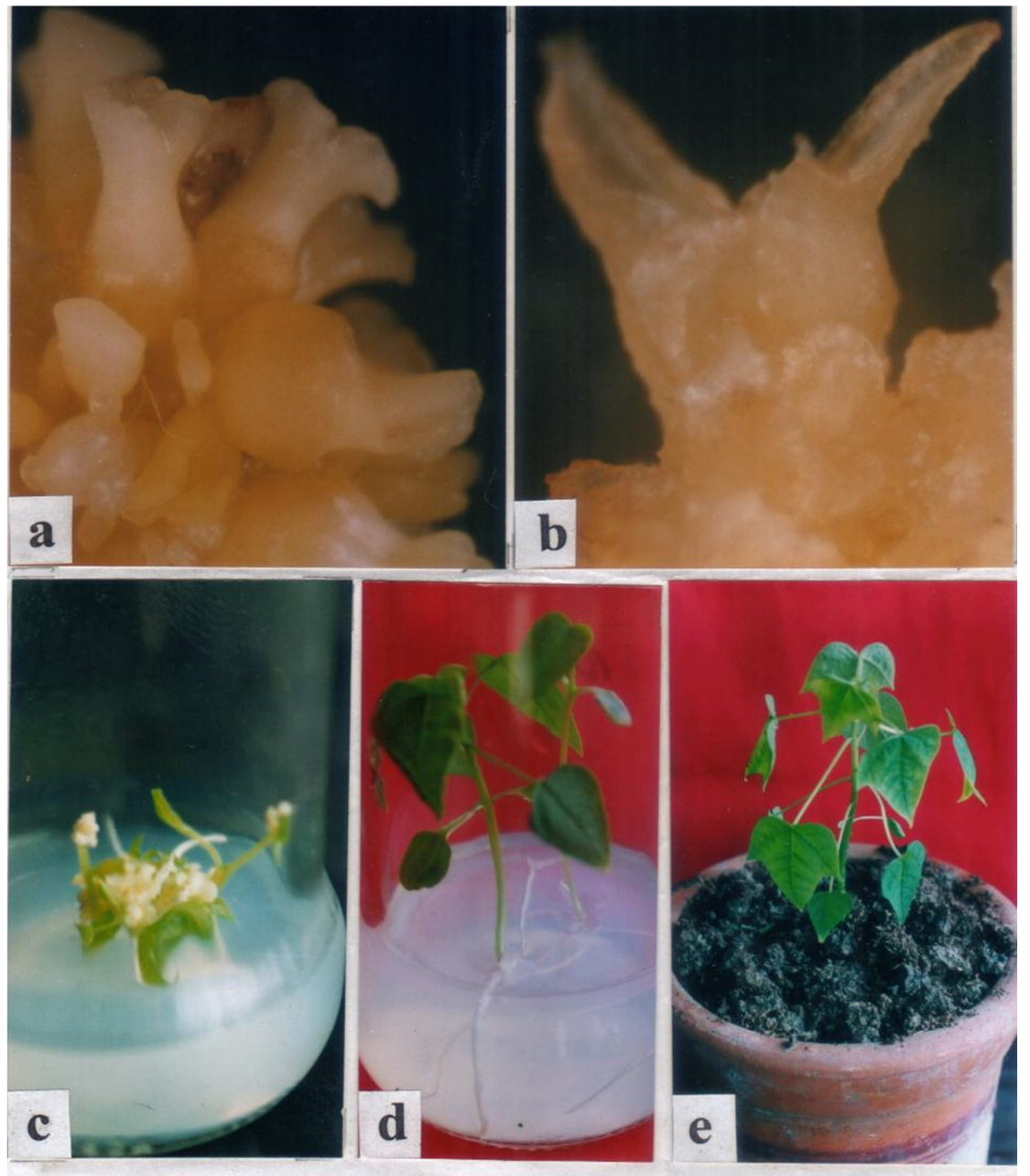

Figure 1. Induction of somatic embryo from immature zygotic embryo of Carica papaya L., cv. Red-Lady (a) Globular, Heart, and Torpedo shaped somatic embryo (b) Cotyledonary shaped somatic embryo (c) Somatic embryos are germinating on germination medium of MSO (d) A complete plantlet from somatic embryo 30 days after culture on rooting medium of MSO (e) Acclimatized plant in potted soil. 
Table 3. Effect of IBA, IAA and NAA on MS supplemented media and MSO and half strength of MS media in root induction of in vitro raised shoots of Carica papaya L. cv. Red-lady at 30 days of inoculation period.

\begin{tabular}{lllll}
\hline Name of hormones & $\begin{array}{l}\text { Concentrations } \\
(\mathbf{m g} / \mathbf{l})\end{array}$ & \% of root inducing shoots & $\begin{array}{l}\text { Average number of root induced/shoot } \\
\text { (Mean } \pm \text { SE) }\end{array}$ & $\begin{array}{l}\text { Average root length/shoot } \\
(\mathbf{c m})(\text { Mean } \pm \text { SE) }\end{array}$ \\
\hline Half strength of MS & - & 40 & $2.25 \pm 0.50$ & $3.50 \pm 0.25$ \\
MS0 & - & 90 & $7.50 \pm 0.75$ & $5.20 \pm 0.40$ \\
IBA & 0.5 & 50 & $3.70 \pm 0.40$ & $3.60 \pm 0.25$ \\
& 1.0 & 30 & $2.60 \pm 0.45$ & $2.90 \pm 0.40$ \\
& 1.5 & 10 & $1.90 \pm 0.30$ & $2.50 \pm 0.60$ \\
IAA & 2.0 & 10 & $2.20 \pm 0.20$ & $1.80 \pm 0.30$ \\
& 0.5 & 10 & $2.40 \pm 0.20$ & $1.50 \pm 0.45$ \\
& 1.0 & 10 & $2.90 \pm 0.40$ & $1.30 \pm 0.40$ \\
NAA & 1.5 & 10 & - & - \\
& 2.0 & 10 & $2.40 \pm 0.70$ & $2.60 \pm 0.30$ \\
& 0.5 & 10 & $2.70 \pm 0.30$ & $1.40 \pm 0.45$ \\
& 1.0 & - & - & $1.25 \pm 0.20$ \\
\hline
\end{tabular}

differentiation or somatic embryogenesis [19]. Somatic embryogenesis of papaya can be obtained from several parts of the plant tissue such as ovules [20], hypocotyl [21], root [6], axillary buds [22], peduncles of mature fruits [23] and immature zygotic embryos [24-25]. The induction of somatic embryogenesis from the vegetative parts of papaya plant was met with low success rates and slow process of regeneration [8]. On the other hand, the induction of somatic embryogenesis from zygotic embryo is more efficient and rapid. This offers the advantage of greatly facilitating mass propagation and artificial seed production technology, which can be applied. High concentrations of 2,4-D and sucrose along with glutamine and also 2,4-D in combination with BA has been reported for the induction of somatic embryogeneis in papaya [13, 26] and [27]. High sucrose concentrations or osmolarity suppress the development of zygotic embryo by inhibiting differentiation of the embryogenic organs, and prevent precocious germination of the embryos [28]. In this study, it was revealed that sucrose concentrations and glutamine has great effect for huge somatic embryo proliferation. Germinated somatic embryo must have functional shoot and root apices capable of meristematic growth. Formation of only shoots or roots might be due to the failure of embryos to form bipolar structures. This might be due to the effect of imbalanced media composition used or timing of explants inoculation or both. It was thought that high concentration of 2,4-D and sucrose along with glutamine changes the metabolic activity of cell or tissue of zygotic embryo of papaya that resulted a mass number of somatic embryo differentiation.

\section{Conclusion}

Carica papaya L. is an economically relevant fruit crop in many tropical and subtropical countries in the world including Bangladesh. This plant shows three polygamous sexual types and commercial production of the fresh fruit is mainly established from hermaphrodite and female lines and 10 to $20 \%$ male lines maintained for effectively pollination of female lines. This cross-pollinating reproductive mechanism exhibited considerable variation in regards to yield, fruit size and quality and also susceptibility to pathogens. Although establishment of somatic embryogenesis protocol from somatic cell other than zygotic cell is the prime objective for the researchers, but this study was conducted to observe the development of somatic embryo from zygotic cell and how does this technique will help for the development of seedlings for the growers and also further improvement of this crop in conjunction with other breeding techniques. An overview of the study reveals that 2,4-D is the powerful plant growth regulator and together with glutamine showed maximum embryogenic response in papaya cv. Red-lady. This study also indicated that zygotic embryo is a good material for inducing somatic embryo directly from the explants tissue and mass production of propagules along with improvement of this crop through this technique is possible. Therefore, induction of somatic embryogenesis may support gene transfer program, mutation breeding, protoplast fusion, creation of somaclonal variations as well as facilitates mass propagation of papaya, although possibility to produce high male plants is concern through this technique. This area also depends on genotypes and zygotic embryo used from the area of the fruit. Zygotic embryo at the middle area of the fruit is shown more effective to produce productive plants. In this investigation, no male plants were observed, but sometimes a few male plants are useful for the fertilization of female plants. Thus, somatic embryogenesis technique developed in this investigation is useful and can try with other papaya genotypes for further improvement of this delicious fruit crop.

\section{References}

[1] Rohani, M. Y., 1994. Papaya: Fruit development, post harvest physiology, handling and marketing in ASEAN. Kualalumpur: ASEAN food handling Buareau.

[2] Canini, A., Alesiani, D., D'arcangelo, G. and Tagliatesta, P., 2007. Gaschromatography-mass spectrometry of phenolic compounds from Carica papaya L. Leaf. J. Food composit Anal. 20(7): 584-590. 
[3] Teixeira da Silva, J.A., Rashid, Z., Nhut, D.T., Siva kumar, D., Gera, A., Souza, Jr.M.T. and Tennant, P.F., 2007. Papaya (Carica papaya L.) biology and biotechnology. Tree ForSciBiotechnol. 1(1): 47-73.

[4] Jimenez, V.M., Mora-Newcomer, E. and Guterrez-soto, M.V., 2014. Biology of the papaya plant. In: Ming R, Moore PH (eds), Genetics and genomics of papaya, Plant genetics and genomics: Crop and Models 10, Springer, New York.

[5] FAO (Food and Agriculture organization of the united nations)/ FAOSTAT, 2010. http://faostat.Fao.Org/site/339/default.aspx.

[6] Chen, M. H. and Chen, C. C., 1992. Plant regeneration from Carica protoplasts. Plant Cell Rep.11: 404-407.

[7] Pang, S. Z. and Sanford, J. C., 1988. Agrobacterium-mediated gene transfer in papaya. J. Am. Soc.Hort. Sci. 113: 287-291.

[8] Fitch, M. M., Manshardt, R. M., Gonzalves, D., Slightom, S. L. and Sanford, J. C., 1990. Stable transformation of papaya via micro projectile bombardment. Plant Cell Rep. 9: 189-194.

[9] Murashige, T. and Skoog, F., 1962. A revised medium for rapid growth and bioassays with tobacco tissue cultures. PhysiologiaPlantarum. 15: 473-497.

[10] Anandan, R., Sudhakar, D., Bala Subramanian, P. and Gutieirrez-Mora, A., 2012. In vitro somatic embryogenesis from suspension cultures of Carica papaya L. ScientiaHorticulturae. 136: 43-49.

[11] Koehler, A.D., Carvalho, C.R., Abreu, I.S. and Clarindo, W.R., 2013. Somatic embryogenesis from leaf explants of hermaphrodite Carica papaya: A new approach for clonal propagation. African journal of Biotechnology. 12: 2386-2391.

[12] Heringer, A.S., Vale, E.M., Barroso, T., Santa-Catarina, C. and Silveira, V., 2013. Polyethylene glycol effects on somatic embryogenesis of papaya hybrid UENF/CALIMAN o1 Seeds. TheorExp Plant physiol. 25(2): 116-124.

[13] Agus, S., 2001. Somatic embryogenesis and protoplast isolation and culture in papaya. M. Sc. Thesis, Department of Crop Science, University Putra Malaysia.

[14] Malabadi, R. B., Kumar, S. V., Mulgund, G. S. and Nataraja, K., 2011. Induction of somatic embryogenesis in papaya (Carica papaya). Research in Biotechnology. 2: 40-55.

[15] Merkle, S. A., Parrott, W. A. and Williams, E. G., 1990. Application of somatic embryogenesis and embryo cloning. In: Plant Tissue Culture: Applications and Limitations, ed., S. S. Bojwani, Elsevier, The Netherlands, pp. 67-101.
[16] Teixeira da Silva J. A., 2016. In vitro response of papaya (Carica papaya) to plant growth regulatots. Nusantara Bioscience. 8(1): 77-82.

[17] Anandan, R., Phan Dinh Phap, Soorianathasundaram, K., Kumar, N., Thirugnanakumar, S., Sudhakar, D. and Balasubramanian, P., 2010. Somatic embryogenesis in Carica papaya through zygotic embryo derived callus culture. Acta Horticulture. 851: 201-208.

[18] Anandan, R., Thirugnanakumar, S., Sudhakar, D. and Balasubramanian, P., 2011. In vitro organogenesis and plantlet regeneration of (Carica papaya L.). Journal of Agricultural Technology. 7(5): 1339-1348.

[19] Ammirato, P. V., 1983. Embryogenesis. In: Hand book of plant cell culture, vol. 1, Macmillan Publishing Co., New York.

[20] Litz, R. E. and Conover, R. A., 1982). In vitro somatic embryogenesis and plant regeneration from Carica papaya in ovular callus. Plant Sci. Lett. 26: 1913-1918.

[21] Yie, S. T. and Liaw, S. I., 1977. Plant regeneration from shoot tips and callus of papaya. In vitro. 13: 564-568.

[22] Jordan, M. and Velozo, J., 1996. Improvement of somatic embryogenesis in highland papaya cell suspensions. Plant Cell, Tissue and Organ Culture. 44: 189-194.

[23] Litz, R. E. and Conover, R. A., 1980. Somatic embryogenesis in cell cultures of Caricastipulata. Hort. Sci. 15: 733-735.

[24] Moore, G. A. and Litz, E., 1984. Biochemical markers for Carica papaya, C. cauliflora, and plants from somatic embryos of their hybrid. J. Am. Soc. Hort. Sci. 109: 213-218.

[25] Chen, M. H., Chen, C. C., Wang, D. N. and Chen, F. C., 1991. Somatic embryogenesis and plant regeneration from immature embryos of Carica papaya x Caricacauliflora cultured in vitro. Can. J. Bot. 69: 1913-1918.

[26] Reuveni, O., Shlesinger, D. R. and Lavi, V., 1990. In vitro clonal propagation of dioecious Carica papaya. Plant Cell, Tissue and Organ Culture. 20: 41-46.

[27] Litz, R. E. and Conover, R. A., 1983. High-frequency somatic embryogenesis from Carica suspension cultures. Ann. Bot. 51: 683-686.

[28] Pliegro-Alfaro, F., Monsalad, M. J. R., Litz, E., Gray, D. J. and Moon, P. A., 1996. Effect of abscisic acid, osmolarity and partial desiccation and the development of recalcitrant mango somatic embryos. Plant Cell, Tissue and Organ Culture. 44: 63-70. 